\title{
A FIELD SURVEYING ON THE GEODETIC CONTROL OF ENGINEERING LINEAR STRUCTURES USING A TERRESTRIAL LASER SCANNER
}

\author{
Oleksandr NAMINAT ${ }^{\circledR}$, Alena PALAMAR (D)* \\ Department of Geodesy, Kryvyi Rih National University, Kryvyi Rih, Ukraine \\ Received 29 October 2018; accepted 03 June 2019
}

\begin{abstract}
The method of geodetic control of the road pavement using TLS is presented. The use of the terrestrial laser scanner can avoid some of the disadvantages of classical methods for determining the deformation of objects. One of the main of them is a small amount of information about the position of individual parts of the object, in this case, linear engineering structures. The proposed technique for terrestrial laser scanning of pavement in order to determine its actual spatial position and real geometric shape allows to perform the required set of works with the least labor and time costs, and also to obtain data for further monitoring. The technique involves the construction of a three-dimensional model of pavement for its evaluation over a certain time interval with a similar model. In order to determine the coordinates by the TLS, the special spheres of known diameter were used. During the measurements, tribrachs on tripods were used, in which the spheres alternately changed to reflectors to eliminate the centering error. The accuracy of determining the coordinates of the temporary survey network relative to the base station was no more than $\pm 27 \mathrm{~mm}$. The accuracy estimation of the temporary survey network coordinates made in the "LeicaGeoOffice" software is presented. The network of permanent stations in Ukraine was used to determine the coordinates, the errors were calculated as the RMS deviation.
\end{abstract}

Keywords: monitoring, terrestrial laser scanner, linear structure, geodetic control, field surveying.

\section{Introduction}

Today, science is making great strides in the development of measuring instruments based on laser-scanning systems, providing qualitatively new opportunities in the tasks of three-dimensional modeling of objects, surveying and geodetic tasks and other fields of application. The development of geodetic instrumentation has led to the emergence of new instruments designed to perform measurements in order to determine the deformations of structures, including digital levels, reflectorless electronic tacheometers, and terrestrial laser scanners (Mill \& Ellmann, 2014; Tsakiri, Lichti, \& Pfeifer, 2006; Ninkov, Bulatović, Sušić, \& Vasić, 2010). The number of enterprises interested in introducing innovative technologies, namely, efficient and high-performance laser scanning systems, is growing. However, the market for such systems provokes their introduction into the practice of surveying and geodetic works without proper scientific, methodological and regulatory justification. In order to introduce new tools into geodesic production, it is necessary to develop methodologies, a study of their main technical parameters and instructions for the productive use of these devices.
Obviously, the development of scientific and practical methodological support for surveying and geodetic works based on modern advances in the field of laser scanning is required, and this is an urgent task demanded by modern production and mining. With the development of scientific and technical progress in geodesic production and the technical level of construction of engineering structures, there is a need to develop and improve the measurement methods and technologies for such monitoring, since the successful solution of this task makes an important contribution to ensuring the reliability, durability, and safety of operation of these facilities. In this regard, the improvement of engineering and geodetic measurements technology for monitoring linear engineering structures is an important task.

The aim is to propose a technique for surveying of linear engineering objects using terrestrial laser scanning, which includes the performing of horizontal and vertical control, selection of the scanning step and the location of the scanner at the station, on the basis of performed experimental and industrial research and to develop an algorithm of actions at each scanner station, which allows to optimize the work of each member of the team and reduce the time of work on the entire facility.

*Corresponding author. E-mail: palamar1alena@gmail.com 


\section{Materials and methods}

At the design stage, the task is arranged and the requirements for the final product are defined: the method of presentation of the product, the requirements for accuracy, the volume of work. Further, the range of tasks, which must be solved in the course of such work as the choice of methods of work, selection of equipment, which by its characteristics would satisfy the stated objectives is determined. Also, information on the points of the initial geodetic network is collected. After receiving this information, the network design of the main horizontal and vertical survey (HVS) is performed, which is created using satellite equipment or electronic tachometers in accordance with the requirements of accuracy, regulated by the instructions. At the stage of the object survey, a reconnaissance is performed, during which an approximate number and position of points of horizontal and vertical control, required to perform surveying are designed. Requirements for the number of points of the horizontal and vertical survey, required for surveying of linear objects using terrestrial laser scanning, are similar to the requirements for performing of topographic surveys using electronic tacheometers.

The study of the authors, in general, represent the obtaining of the points cloud with noise reduction and the point calibration approach, which uses a large number of measured points in space and time (4D). The aim is to detect any movement using terrestrial laser scanning (TLS) data with obtaining of sub-cm precision or small local objects with sub-mm precision (Dumalski \& Hejbudzka, 2010; Linh \& Laefer, 2014; Mill \& Ellmann, 2014; Tsakiri et al., 2006; Abellán, Jaboyedoff, Oppikofer, \& Vilaplana, 2009; Ninkov et al., 2010). This technique can be used to study small natural or man-made changes in shape or spatial position, deformations in mountain slopes or pit walls, minor movements of the earth's surface or road pavement in any direction. The software algorithm calculates horizontal distances and, due to excessive measurements, uses a point cloud calibration kit to remove systematic errors. Then the median of the resulting points in space is used, which allows to filter the values in space and time and reduce the rough errors. The quality of the application of this algorithm is confirmed by theoretical and experimental examples. Optimal combinations of resulting spatial and temporal data in practical tasks can lead to improved measurement results by several orders, which will significantly improve the detection of small changes in many deformation processes, such as deformation of the upper layer of the earth's surface, deformation in engineering and civil structures and various geomorphological changes. In the process of data obtaining during measurements, there is always a random noise, usually due to the roughness of the object or some natural obstacles, which are usually filtered programmatically by the averaging method. It is important to note that there are two methods for averaging cloud point results. The first is directly averaging the position of the point cloud over the constructed grid formed by smoothing (a smoothing grid) and averaging using the average difference between neighbouring points in the cloud (Song, Zheng, D. Li, Chen, \& L. Li, 2015).

The combination of spatial data and temporal component has a great advantage over these two components separately. In particular, it was found that in the presence of spatial connections, the accuracy of the data of individual points increases (Alba, Roncoroni, \& Scaioni, 2008; Neitzel, 2006). Therefore, as the number of neighbouring connections increases around one point at different times, averaging the results of determining the position of this point becomes closer to the true value. For example, on average, 10 points will have 100 adjacent spatial connections, this will lead to a decrease in the standard deviation error by 32 times. But this data can be applied only if there is a normal Gaussian distribution, which is almost impossible when scanning the terrain (Ko \& Lee, 1991). This is due to the different structure of the surface, its roughness, the presence of vegetation or other obstacles.

The object of scanning is a road "Tekhbaza - West Cemetery", which is located in the Kryvyi Rih city of Dnipropetrovsk region. To solve the problem of geodetic control of this engineering object, the method of terrestrial laser scanning is proposed, which allows reducing the number of geodetic instruments and will allow to determine various parameters of the object, which can be classified as follows: geometric parameters of the object (length, width, height, area, volume); local deformations of the object (torsion, crack opening, distinct from the main surface); the relative position of objects in the area of the survey (the difference in the precipitation of marks, the change in the location of objects that are nearby, the registration of cracks, if any); the spatial position of engineering structures (deviation from vertical pillars change of fences and bridges positions); determination of the displacement direction and rate of deformations (determination of the rate of the position change of objects individual sections).

According to the recommendations of Ministry of Emergencies of Ukraine (2012) the instrumental observations at the station consist of horizontal and vertical bridging of reference benchmarks to the starting points and periodic monitoring of their immobility during the period of the observations; initial observations to determine the initial position of the observation station benchmarks in the horizontal and vertical planes; repeated observations of the position of the observation station benchmarks; periodic surveys of cracks, dips and areas of the collapse of the earth's surface. Today, in Ukraine there are no normative documents, which clearly regulate the work of TLS. Obviously, the development of justified scientific and practical methodological support of surveying and geodetic works on the basis of modern advances in the field of laser scanning is required and this is an urgent task demanded by modern production and mining operations. 


\section{Field studies of the TLS accuracy characteristics on the example of the Leica Scan Station 2}

The method of geodetic control of the road with the use of TLS includes: reconnaissance of the object on which the work is carried out, the design of work and the definition of tasks that need to be solved; selection of objects to be controlled, their parameters and the process of their control; development of a scanning scheme, identification of work stages; analytical or instrumental determination of several static geometric elements located on the object of control or those, which are in close proximity to the installation site of the TLS, and which comply with the lack of its geometry dynamics and not subjected to deformations for a long time (1-2 seasons); calculations of theoretical measurement accuracy, impact assessment, which degrade the accuracy of TLS measurements, described previously and determining the expected error; selection of the processing method for the performed measurements and forms of reporting documentation for the work performed on the object; field surveying on the geodetic control (preparation of TLS, fixtures and special equipment; safety activities); processing and analysis of measurement results (performing of reprocessing for TLS measurement results; determining the geometric characteristics of the object of scanning and its shape as a whole for the subsequent creation of the model; the acquired data analysis).

If it is possible to shoot an object from one standing point, that is, to acquire one scan, then the essence of the technique is as follows. Shooting by terrestrial laser scanner from one station in conditional scanner coordinate system is performed. Then a detailed survey on the characteristic elements of the scanned object, which are similar to regular geometric shapes, in order to obtain the control virtual points is required.
The characteristics of the object should be considered in order to select the optimum scan position. First, points with direct visibility are determined, on which marks for orientation and cross-linking of scans can be placed, and then an object is scanned. Sections of complex shape are shoot in more detail, as well as distant parts.

Choosing the optimal scan characteristics will eliminate a certain number of errors and improve the final results. To this end, it is proposed to use the following recommendations obtained in the course of experimental studies:

1. Perform the scanner warm-up for 15 minutes if the air temperature is less than $+25^{\circ} \mathrm{C}$.

2. Areas, which are needed to be monitored, in most cases, should be located within the measured distance, which is 8-60 meters, these limits can be extended to 5-80 meters under favorable conditions for measurements. This is due to the fact, that exactly at these distances the optimum angles of signal sending and receiving by the device, on which data errors have a stable value are maintained. Conclusions on such ranges of distance choice were selected after the field experiment. On the territory, the basis with benchmarks was divided on the distances from the scanner of $5 \mathrm{~m}, 10 \mathrm{~m}$, and further by every 10 meters up to 120 meters, so 13 benchmarks were obtained. Horizontal coordinates and vertical control points are obtained using tacheometer and level in a common coordinate system (Meier et al., 2010). The installation height of the scanner was 1.80 (Figure 1).

The resulting deviations of the coordinates calculated after the measurements are shown in Figure 2. In order to determine the coordinates by the TLS, the special spheres of known diameter were used. After scanning of these spheres, at the cameral processing in an automatic mode, their centers were determined. The centers of the

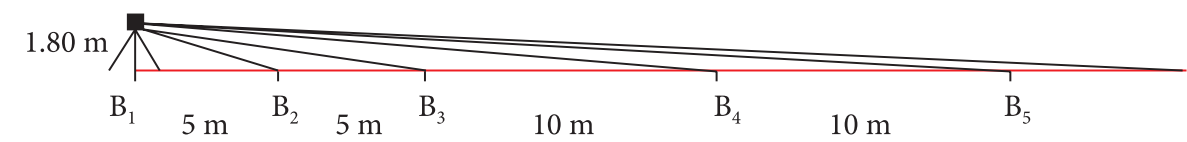

Figure 1 . The pattern of scanner location relative to benchmarks

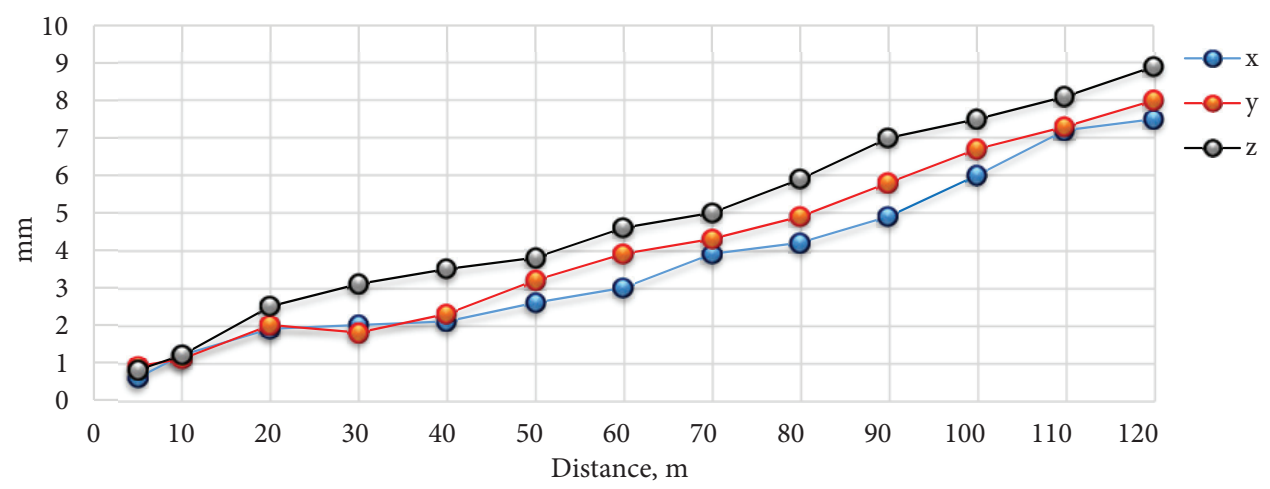

Figure 2. The resulting deviations of the coordinates 
reflector were determined by the tacheometer. During the measurements, tribrachs on tripods were used, in which the spheres alternately changed to reflectors to eliminate the centering error.

By analyzing this graph, we can conclude that the sharp change in the coordinates of the points deviation occurs in the interval of 50-60 meters. Further with increasing distance, the deviation grows faster. Also, the high rate of error increase is observed at intervals of 5-20 meters. Considering these experiments, an optimal measurement distance has been proposed;

3. For a more accurate positioning of the benchmark when scanning, it is proposed to use the benchmarks or focus on rigidly fixed objects in the field of view of the scanner, which have a visible scan area of more than $6 \mathrm{~cm}^{2}$, and, if possible, choose such objects whose shape is close to regular geometric shapes. Such a benchmark has at its end a mark in the form of a cube, the dimensions of which may be different but always known, which will make it possible to clearly compare the dimensions obtained

The laser point Defined border Regular geometric shape

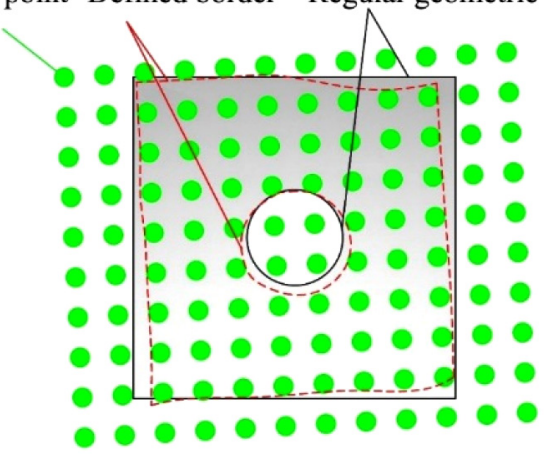

Figure 3. Determining the boundaries of the scanned benchmark during measurements. The depth of the benchmark and its length can be arbitrary, depending on the task, and the area of work. For more accurate modeling, during data processing, a hole is made in the center of benchmark from 5 sides, which will allow make additional control in determining the center of benchmark from either side of the scan. Such holes, allow to increase the efficiency of finding the coordinates of the benchmark center for its further analysis in determining the deformation processes;

4. Benchmarks must be correct and known shapes and sizes. During the experiments, it was found that the most accurate results of benchmarking from the scan are presented by objects with an area of more than $9 \mathrm{~cm}^{2}$. Figure 3 shows the errors, which occur during the processing of scanned objects.

5. Make sure that the angle of incidence on areas that need to be controlled does not exceed $50^{\circ}$, since at large angles, the returning signal weakens considerably, and this leads to the occurrence of uncontrollable errors in data acquisition.

6. Eliminate the tripod vibration as much as possible, which is quite important in the case of the road, using rubber pads under the tripod.

7. Perform at least three measurements repetitions on monitored objects, with a scan resolution of at least 10 points per $1 \mathrm{~cm}^{2}$.

8. It is desirable to choose (paint) benchmarks or areas for control of bright colours to avoid a high percentage of rays absorption.

9. Follow operating instructions of the scanner (in my case - Leica Scan Station 2 (Leica-geosystems, 2018).

10. Directly before scanning, the HVS at the object of study was created (Figure 4). Then scanning from fixed and coordinated points on the terrain is performed.

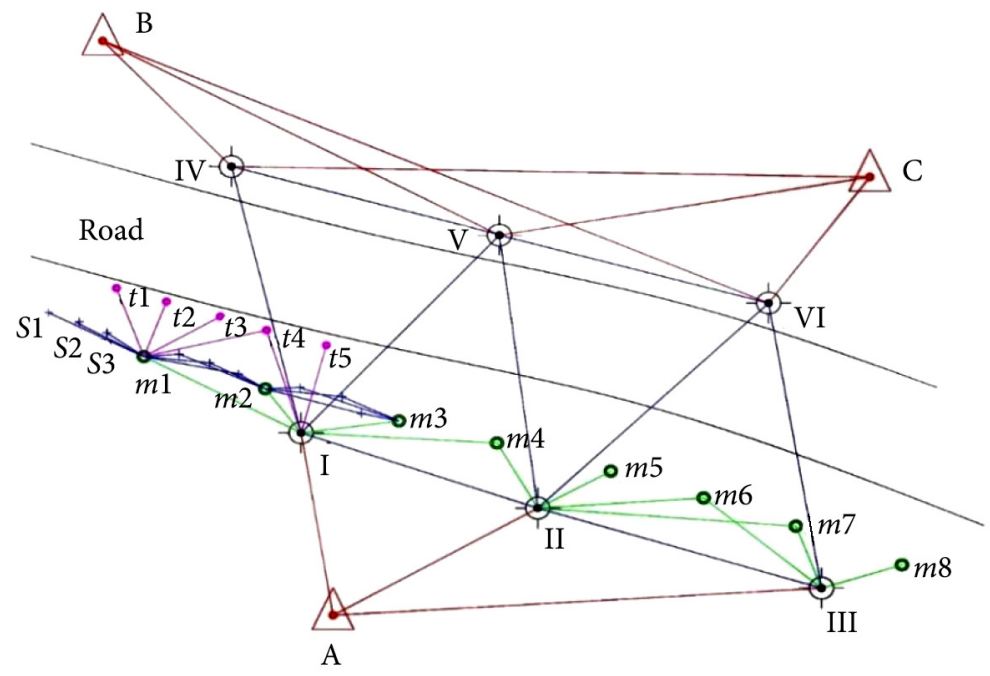

Figure 4. The scheme of HVS creation

In this figure: $\mathrm{A}, \mathrm{B}, \mathrm{C}$ - are the points of the state geodetic network; I, II, VI - are the basic HVS,

$S_{1,2,3}$ - are the scanner stations; $m 1, m 2$ - are the operating HVS of scanner stations, $t 1 \div t 5$ - are the acquired points. 
Let's consider the scanning sequence, which was used on the road "Tekhbaza - West Cemetery":

1. Panoramic shooting on TLS camera and scanning with a large step of $10-20 \mathrm{~cm}$, horizontally and vertically at a distance close to $100 \mathrm{~m}$.

2. The measurement of the distance from the TLS to the control elements using the "Distance" function. These actions are automatically recorded in the menu, which allows adjusting the scan settings and more accurately determine the scan step.

3. The 10-fold scanning of control marks, benchmarks or control areas using the "window scan" option, which allows setting the scanning area using the previously obtained image using the TLS camera.

4. Scanning of benchmarks and marks used for crosslinking of individual scans and control areas with a maximum scanner resolution.

5. After one hour, in order to control the dynamic processes at the scanning station, it is necessary to conduct one more observation of benchmarks with the maximum resolution of the scanner and objects, which are not subjected to deformation.

6. After completion of the scanning, the possible gaps that have arisen during the movement of cars or other obstacles are found and additionally scan these areas, and only then turn off the scanner.

The coordinates of the points over which the scanner was installed and observations were made must be monitored by other geodetic instruments (tacheometer, level, GPS-receivers, etc.). During the scanning, it is necessary to always monitor and record the atmospheric phenomena, which affect the work of geodesic rangefinders. But the standard impact on the accuracy of distance measurements when using a laser rangefinder is about $5 \mathrm{~mm}$ per $1 \mathrm{~km} \pm 0.1 \mathrm{~mm}$; therefore, this value is not significant when using TLS at a maximum distance of up to $100 \mathrm{~m}$ from the scanned object (Voronin, Sinyakin, \& Ustyugov, 2004). The object of observation was a section of road pavement with a hard surface (asphalt) about $1200 \mathrm{~m}$ long ("Tekhbaza - West Cemetery"). This section of the road passes over the voids, which are formed by the underground mining of ore-bearing rocks and is bordered by landslide zones. To identify possible (forecasted) vertical and horizontal deformations of the road in the area under study, the newest method of terrestrial 3D laser scanning was selected.

The reconnaissance of the area of work was carried out by a group of specialists from a research and production company LLC Doka, in the presence of scientists from Kryvyi Rih National University. In the surveyed part, the road runs from the west to the east along the middle cross-country terrain in a park area with broad-leaved trees, which are more than $8 \mathrm{~m}$ high. In the observation area, the height of the road pavement above the natural level of the soil ranges from $0.5 \mathrm{~m}$ to $1.5 \mathrm{~m}$ and up to $3 \mathrm{~m}$ at the iron-concrete bridge $12 \mathrm{~m}$ long, which falls into the scan area. The width of the road (with a roadside) ranges from 10 to $12 \mathrm{~m}$, the width of the hard surface (asphalt) is from 6 to $7.5 \mathrm{~m}$. The roadside is partially covered with grass, which makes it difficult to recreate all the road pavement according to the scan results and leads to a decrease in the accuracy of the TIN-model construction at the grass-covered areas of the road. Hard road cover is partially damaged and needs to be repaired. To install the scanner and flat reflector marks at the first stage of work 20 points of the temporary survey network are scheduled on the roadside and fixed with steel rods with a diameter of $16 \mathrm{~mm}$ and a length of $0.5-0.7 \mathrm{~m}: 7$ scanning stations, 13 marks installation points (3-4 per station, on each side of the road) for "cross-linking" of the separate scans (point clouds). The diagram of the points of the temporary survey network used during the 5th stage of scanning is shown in Figure 5.

After the first stage of scanning, during the processing of the results, it was concluded that there is a need to increase the number of points of the temporary survey network on which the reflector marks are installed to improve the accuracy of cross-linking point clouds. For a reliable determination of polygonometry points coordinates, which are determined by several geodetic methods, it is decided to install two reflecting marks on each point on a metal rod in a vertical position. After these solutions, using navigational equipment in static mode, the coordinates of additional points of the temporary survey

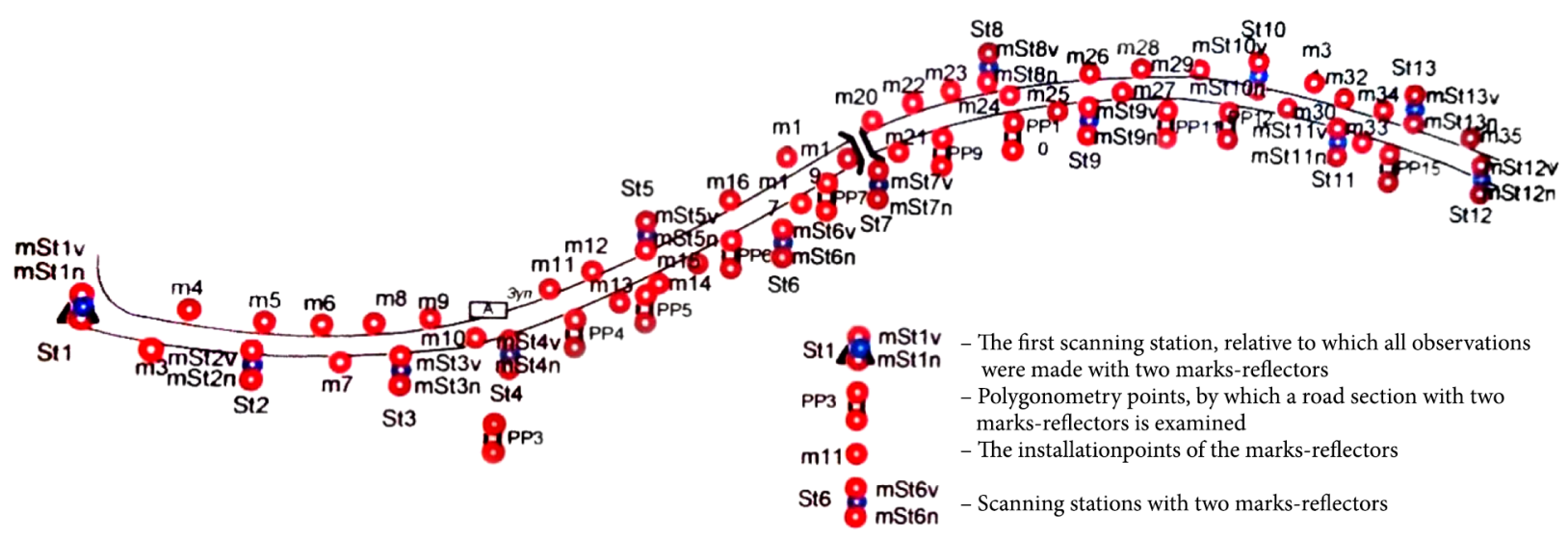

Figure 5. Installation scheme of temporary survey network points 
network were determined, and which were included in the total cloud points of the terrestrial laser scanner. In addition to increasing the control accuracy, the additional points of the survey network allow increasing the number of visible points of polygonometry for their comparative analysis. The scheme of points bridging, and the accuracy of the results obtained are shown in Table 1 and in Figures 6 and 7 .

Thus, the accuracy of determining the coordinates of the temporary survey network relative to the base station was no more than $\pm 27 \mathrm{~mm}$. The network of permanent stations in Ukraine was used to determine the coordinates, the errors were calculated as the RMS deviation. Studies on the profile line with 16 points allowed us to draw initial conclusions for further more in-depth research.

\section{Conclusions}

The sequence of actions on each scanner station has been developed, which allows to optimize the operation and reduce labor costs in the performance of the overall survey by $15-20 \%$. When using this sequence of actions, the time for the road pavement scanning with a length of $1200 \mathrm{~m}$ was reduced from 20 hours to 15 hours comparing the

Table 1 . The accuracy estimation of the temporary survey network coordinates made in the "LeicaGeoOffice" software

\begin{tabular}{|c|c|c|c|c|c|c|}
\hline \multicolumn{7}{|c|}{ 1-st scanning } \\
\hline Name and number & Status & Date and time & $\mathrm{Y}, \mathrm{m}$ & $\mathrm{X}, \mathrm{m}$ & $\mathrm{H}, \mathrm{m}$ & $\Delta_{\mathrm{RTK}}, \mathrm{m}$ \\
\hline Baganovo3kl & Control & 05/26/2011 11:26:58 & 4371147.189 & 5306639.8360 & 102.435 & 0.000 \\
\hline Dubovabalka $1 \mathrm{kl}$ & Measured & 05/26/2011 17:10:24 & 4365662.909 & 5310036.776 & 121.982 & 0.001 \\
\hline Pp17st6 & Measured & 05/26/2011 16:20:08 & 4365604.068 & 5304900.098 & 96.743 & 0.001 \\
\hline Pp 19 & Measured & 05/26/2011 15:41:09 & 4365721.399 & 5304876.996 & 95.633 & 0.001 \\
\hline Pp 18 & Measured & 05/26/2011 16:00:37 & 4365665.688 & 5304896.042 & 96.549 & 0.003 \\
\hline Pp 20 & Measured & 05/26/2011 15:10:36 & 4365790.005 & 5304864.504 & 94.496 & 0.003 \\
\hline Pp 5st1 & Measured & 05/26/2011 13:57:54 & 4364767.498 & 5304676.447 & 98.887 & 0.016 \\
\hline Pp 3 & Measured & 05/26/2011 14:11:14 & 4364887.230 & 5304666.177 & 99.308 & 0.018 \\
\hline Pp 1 & Measured & 05/26/2011 13:59:28 & 4364798.187 & 5304691.357 & 99.286 & 0.020 \\
\hline Pp 19kont & Measured & 05/26/2011 12:22:50 & 4365721.381 & 5304877.034 & 95.653 & 0.024 \\
\hline Dubovabalka $1 \mathrm{kl}$ control & Control & 05/26/2011 17:10:24 & 4365662.817 & 5310036.872 & 121.107 & 0.000 \\
\hline \multicolumn{7}{|c|}{ 2-nd scanning } \\
\hline M5st1 & Reference & 07/19/2011 20:01:50 & 4364767.4979 & 5304676.4469 & 98.8862 & 0.0000 \\
\hline $\mathrm{St} 3 \mathrm{~m} 7$ & Measured & 07/19/2011 20:18:12 & 4364998.3947 & 5304667.5159 & 98.1530 & 0.0167 \\
\hline St $4 \mathrm{~m} 10$ & Measured & 07/19/2011 20:21:19 & 4365090.8563 & 5304678.3967 & 96.1898 & 0.0167 \\
\hline Pp 1 & Measured & 07/19/2011 20:02:43 & 4364798.1682 & 5304691.3159 & 99.2592 & 0.0169 \\
\hline St2m3 & Measured & 07/19/2011 20:04:58 & 4364887.2181 & 5304666.1601 & 99.2694 & 0.0174 \\
\hline St6m16 & Measured & 07/20/2011 15:14:36 & 4365281.6865 & 5304768.1587 & 95.2027 & 0.0175 \\
\hline St5m13 & Measured & 07/19/2011 20:24:57 & 4365184.4418 & 5304726.4418 & 95.0763 & 0.0188 \\
\hline St8m 22 & Measured & 07/20/2011 15:24:29 & 4365453.7750 & 5304870.0737 & 96.0638 & 0.0194 \\
\hline Pp 2 & Measured & 07/19/201120:03:43 & 4364824.9448 & 5304671.2996 & 99.1112 & 0.0200 \\
\hline $\mathrm{Pp} 4$ & Measured & 07/19/2011 20:07:12 & 4364914.8353 & 5304663.6176 & 99.1851 & 0.0203 \\
\hline St11m31(m19) & Measured & 07/20/2011 15:32:59 & 4365721.3440 & 5304876.9666 & 95.6345 & 0.0212 \\
\hline St7m19 & Measured & 07/20/2011 15:16:42 & 4365373.8217 & 5304824.6633 & 95.9650 & 0.0251 \\
\hline St9m25 & Measured & 07/20/2011 15:26:54 & 4365554.2247 & 5304887.7101 & 96.7804 & 0.0259 \\
\hline St12m34 & Measured & 07/20/2011 15:38:17 & 4365874.7911 & 5304849.0046 & 93.9524 & 0.0277 \\
\hline $\mathrm{St} 32(\mathrm{~m} 20)$ & Measured & 07/20/2011 15:36:47 & 4365790.0086 & 5304864.5032 & 94.4916 & 0.0283 \\
\hline St10m28 & Measured & 07/20/2011 15:29:49 & 4365635.2966 & 5304898.4448 & 96.5533 & 0.0303 \\
\hline \multicolumn{7}{|c|}{ 3-rd scanning } \\
\hline M5st1 & Reference & 08/15/2011 15:32:29 & 4364767.498 & 5304676.447 & 98.887 & 0.0000 \\
\hline St $3 \mathrm{~m} 7$ & Measured & 08/15/2011 13:09:35 & 4364998.390 & 5304667.510 & 98.155 & 0.0191 \\
\hline St $4 \mathrm{~m} 10$ & Measured & 07/19/2011 13:17:51 & 4365090.861 & 5304678.394 & 96.195 & 0.0165 \\
\hline Pp 1 & Measured & 07/19/2011 12:50:43 & 4364798.173 & 5304691.311 & 99.265 & 0.0171 \\
\hline
\end{tabular}




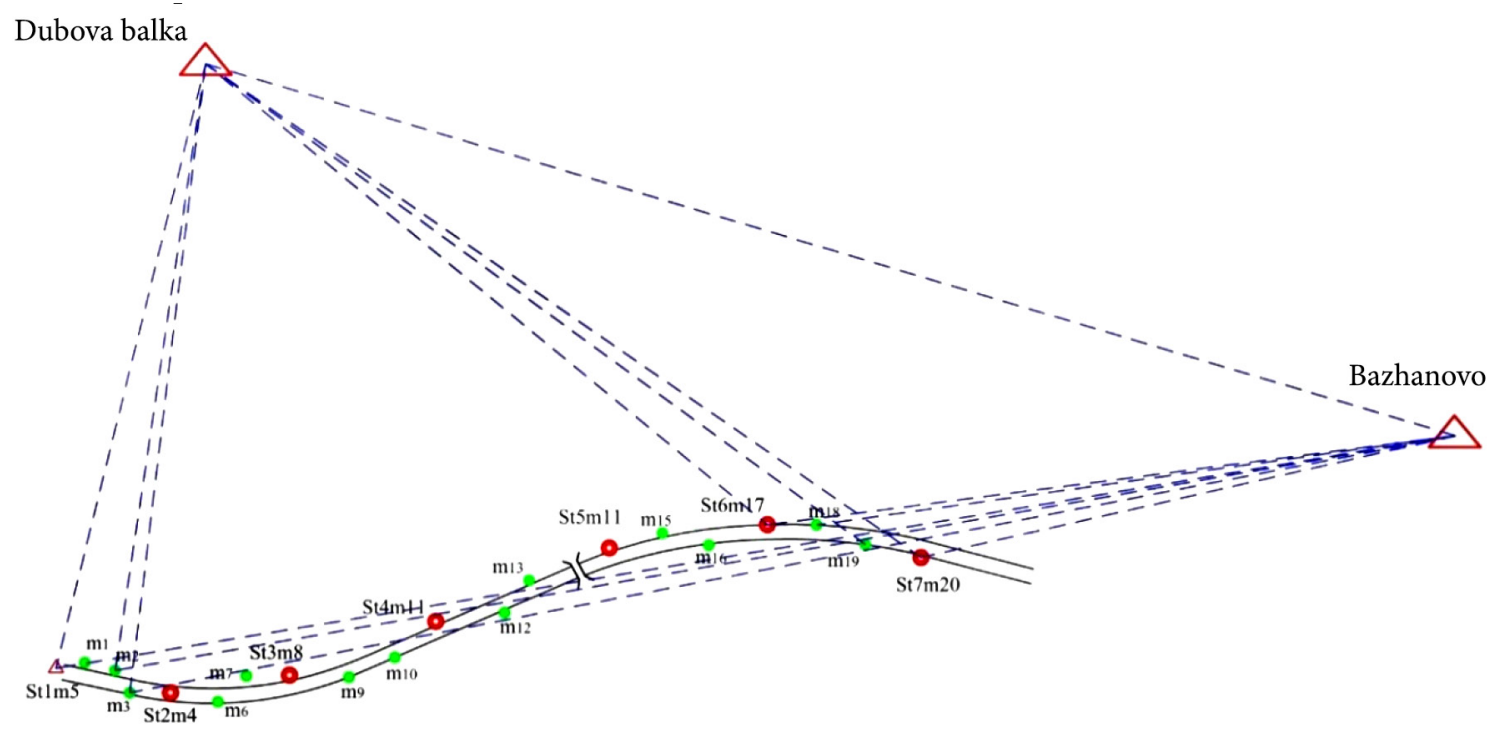

Figure 6. Bridging of temporary survey network to the state geodetic network

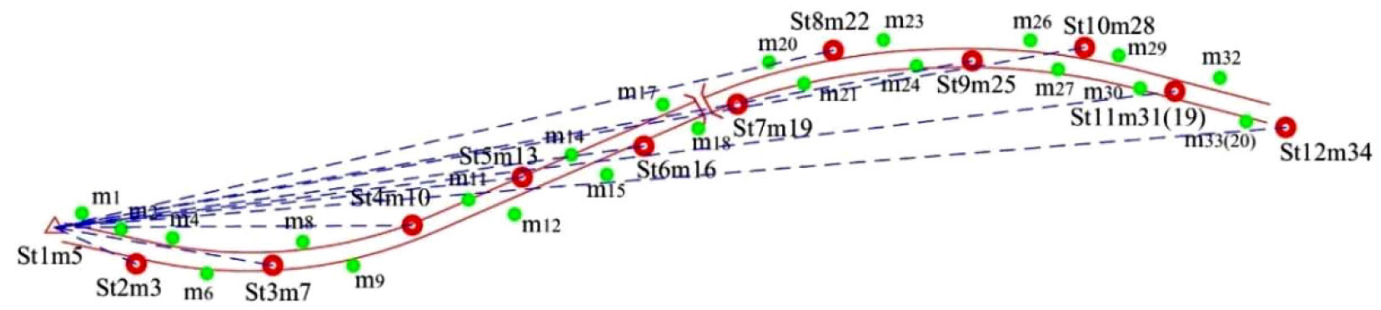

Figure 7. Scan points bridging

first series of observations with the second one. At the same time, it should be noted that by using TLS we analyze almost 2 million points of road pavement, and using classical observation methods, only 30 points of the profile line, which laid down along the curb. The time costs are less with TLS. The sedimentation rate of this section of the road is $25-50 \mathrm{~mm} /$ year, therefore, the obtained TLS accuracy of the road pavement, fully satisfies the tasks and can replace observations on profile lines at similar facilities. Given the detail and amount of data obtained, it can be said with confidence, that the identification of problem areas will be much more effective and will allow timely response to prevent local man-made disasters. The use of digital plans for their further use in order to monitor the change in the position of the road hard surface in time and space is proposed. Recommendations for scanning errors minimization by choosing the optimal scan characteristics and improvement of the accuracy of the final result are given.

\section{Funding}

The research has no funding.

\section{Author contributions}

Oleksandr Naminat conceived the study and was responsible for the design and development of the data analysis. Alena Palamar was responsible for data interpretation.

\section{Disclosure statement}

Authors have no competing financial, professional, or personal interests from other parties.

\section{References}

Abellán, A., Jaboyedoff, M., Oppikofer, T., \& Vilaplana, J. (2009). Detection of millimetric deformation using a terrestrial laser scanner. Experiment and application to a rockfall event. Natural Hazards Earth System Sciences, 9, 365-372. https://doi.org/10.5194/nhess-9-365-2009

Alba, M., Roncoroni, F., \& Scaioni, M. (2008). Investigations about the accuracy of target measurement for deformation monitoring. The International Archives of the Photogrammetry, Remote Sensing and Spatial Information Sciences, 37(Part B5), 1053-1059.

Dumalski, A., \& Hejbudzka, K. (2010, April 11-16). An attempt at using a terrestrial laser scanner for detecting minimal displacement and objects deformations. Paper presented at the 
Proceedings of Facing the Challenges - Building the Capacity, Sydney, Australia. Poland.

Ko, S. J., \& Lee, Y. H. (1991). Center weighted median filters and their applications to image enhancement. IEEE Transactions on Circuits and Systems, 38(9), 984-993.

https://doi.org/10.1109/31.83870

Leica-geosystems. (2018). Leica TPS400 Series Easy, quick, reliable and powerful. Retrieved from https://www.leicageosystems.com/common/shared/downloads/inc/downloader.asp?id=2226

Linh, T., \& Laefer, D. (2014). Application of terrestrial laser scanner in bridge inspection: review and an opportunity. In 37th IABSE Symposium: Engineering for Progress, Nature and People (pp. 2713-2720), Madrid, Spain, 3-5 September. International Association for Bridge and Structural Engineering. https://doi.org/10.2749/222137814814070190

Meier, E., Geiger, A., Ingensand, H., Licht, H., Limpach, P., Steiger, A., \& Zwyssig, R. (2010). Hydrostatic levelling system: measuring at the system limits. Journal of Applied Geodesy, 4(2), 91-102. https://doi.org/10.1515/jag.2010.009

Mill, T., \& Ellmann, A. (2014, April 3-4). Terrestrial laser scanning technology for deformation monitoring of a large suspension roof structure. Paper presented at the INGEO 2014 - 6th International Conference on Engineering Surveying Prague, Czech Republic.
Ministry of Emergencies of Ukraine. (2012). Methodological recommendations for the protection of mineral resources in the development of mineral deposits (No. 1268). Retrieved from https://zakon.rada.gov.ua/rada/show/en/v1268735-12/ sp:max 20

Neitzel, F. (2006). Investgation of axes errors of terrestrial laser scanners. Paper presented at the 5th International Symposium Turkish-German Joint Geodetic Days, Berlin.

Ninkov, T., Bulatović, V., Sušić, Z., \& Vasić, D. (2010, April 1116). Application of laser scanning technology for civil engineering projects in Serbian. Paper presented at the FIG Congress 2010 Facing the Challenges - Building the Capacity Sydney, Australia.

Song, B., Zheng, N., Li, D., Chen, R., \& Li, L. (2015). Reconstructing DEM using TLS point cloud data and NURBS surface. Transactions of Nonferrous Metals Society of China, 25(9), 165-172. https://doi.org/10.1016/S1003-6326(15)63947-4

Tsakiri, M., Lichti, D., \& Pfeifer, N. (2006, May 22-24). Terrestrial laser scanning for deformation monitoring $3 r d$ IAG. Paper presented at the 12th FIG Symposium, Baden.

Voronin, M., Sinyakin, A., \& Ustyugov, M. B. (2004). External and internal effects on optical-electronic devices and their testing. Novosibirsk: SSGA. 